Diversity of Research in Health Journal /Revue de la Diverstité de la Recherche en Santé

\title{
Nursing Processes Related to Unexpected ICU Admissions
}

\section{J. Martin, R. Heale, N. Lightfoot, L. Hill}

Jennifer Martin, RN, MScN

jennifermartin@sympatico.ca

Laurentian University

Roberta Heale, NP-PHC, DNP, PhD

Associate Professor

rheale@laurentian.ca

Laurentian University

Nancy Lightfoot, PhD, F.A.C.E.

Associate Professor

nlightfoot@laurentian.ca

Laurentian University

Laura Hill, MScN, NP-Adult

Health Sciences North/Horizon santé nord

lhill@hsnsudbury.ca 


\begin{abstract}
Nurses have the knowledge and skills to recognize and intervene when the condition of patients on medical or surgical units deteriorates. Despite this, deterioration is sometimes missed resulting in unexpected ICU admissions. This study explored the nursing process factors associated with unexpected ICU admissions. A chart audit was undertaken in a large urban hospital and data were collected measuring nursing assessment (vital signs), communication and documentation. Results showed that the most common reason for an unexpected ICU admission was respiratory distress. At the same time, respiratory rate was the least documented vital sign. Communication, documentation and recognition of patient deterioration play a key role in intervening and preventing unexpected ICU admissions. Attention to adequate staffing levels as well as implementation of clinical tools may assist nurses to more readily address patient deterioration and prevent unexpected ICU admissions.
\end{abstract}

Key words: Nursing processes, Patient deterioratation

\title{
Résumé
}

Les infirmières et les infirmiers ont les connaissances et les compétences à reconnaître et intervenir lorsque l'état des patients sur les unités médicales ou chirurgicales se détériore. Malgré cela, la détérioration est parfois manquée, qui entraîne des admissions inattendues à l'USI. Cette étude a exploré les facteurs liés au processus de soins associés aux admissions inattendues en unité de soins intensifs. Un audit des dossiers a été effectuée dans un grand hôpital urbain et des données ont été recueillies pour mesurer l'évaluation des soins infirmiers (signes vitaux), la communication et la documentation. Les résultats ont montré que la raison la plus fréquente d'admission inattendue à l'USI était la détresse respiratoire. En même temps, la fréquence respiratoire était le signe vital moins documenté. La communication, la documentation et la reconnaissance de la détérioration du patient jouent un rôle essentiel dans l'intervention et la prévention des admissions inattendues à l'USI. L'attention portée aux niveaux de dotation adéquats ainsi que la mise en œuvre d'outils cliniques peuvent aider les infirmières et les infirmiers à aborder plus facilement la détérioration du patient et à prévenir les admissions inattendues à l'USI. 


\section{Introduction}

People are hospitalized for a variety of reasons such as to receive specialized medical testing, to receive expert care in the stabilization of a medical condition, to recover from surgery and more. Not all patients are in a critical state, requiring them to be in the intensive care unit (ICU). However, there are times when a patient's condition deteriorates while they are hospitalized and they require admission, or readmission, to critical care. Patients readmitted to the ICU during their hospitalization have a 19\% higher rate of mortality, longer length of stay and a prolonged recovery post discharge (Johns 2014, Garland et al. 2013). A number of health related issues including: cognitive dysfunction, sleep issues, depression, post traumatic distress syndrome or ICU acquired weakness may persist even upon discharge. Collectively called Post Intensive Care Syndrome, these issues may last for a year or more following a critical illness (Elliott et al. 2014, Bradford \& Grassi 2009) and unfortunately some patients may never recover (Harvey 2012, Bradford \& Grassi 2009).

Remaining on the ward while critically ill has been shown to be an independent predictor of mortality (Johns 2014, Jäderling et al. 2013) and one contributor to unexpected ICU admissions is a lack of recognition of the deterioration and delayed care (Mok et al. 2015). However, early detection of deteriorating patients on the wards can result in the prevention of an ICU admission (Soar \& Subbe 2012). Given the increased risk for negative outcomes or death, it is prudent to prevent patients from requiring the need for unplanned ICU admissions as much as possible, or proactively admit to ICU prior to critical deterioration of the patient's condition. Nurses who work with patients on wards are in an ideal position to identify patient deterioration and implement processes that may prevent further deterioration and the need for ICU admission. This study focused on patients who had been unexpectedly admitted to ICU from a hospital ward. It focused on an evaluation of nursing processes, including vital signs and communication with the critical care response team and physicians, and their relationship to the unexpected ICU admissions.

\section{Background}

Early anticipation and prevention of adverse events are critical components of patient safety and central to the role of the nurse within the hospital system (Mok et al. 2015, Boyle 2004). Nurses assess, anticipate, intervene and apply clinical judgment (Ashcraft 2004) and are in a key position to detect changes and improve patient outcomes (Mok et al. 2015, Mapp et al. 2013). Detection of patients who are clinically deteriorating can often be identified hours before an admission to the ICU from the ward becomes necessary. Early recognition and correction of physiological abnormalities can aid in the prevention of the deterioration of patients (Mok et al 2015, Considine 2005) and avoidance of unplanned ICU admissions. Several authors have suggested that failure to recognize, and therefore act, on the deterioration of patients, results in suboptimal care for critically ill patients on wards (Mok et al. 2015, Considine 2005). Delayed admission to the ICU has a significant impact on patient morbidity and mortality (Mapp et al. 2013, Cuthbertson et al. 2007, 
Jeffs et al. 2005). Deaths have resulted in part from lack of observation, documentation, and recognition of deterioration as well as a lack of communication between health care providers (Mapp et al. 2013).

Ongoing monitoring is essential. For example, prior to cardiac arrest events there are often physiological changes present in vital signs for four, eight or more hours (Mapp et al. 2013, Ludikhuize et al. 2012). It has also been realized that hypotension, tachypnea and tachycardia are the most common precursors to hospital deaths. Recognition of changes in vital signs is paramount in correcting and preventing adverse events from occurring (Buist et al. 1999).

Respiratory failure is the most common reason for unplanned ICU admissions (De Meester et al. 2013, Jonsson et al. 2011). Ratray et al, (2011) found that for most nurses the identification of one variable, such as a change in respiratory rate, did not typically trigger the need for further assistance for a patient. Nurses tended to gather multiple data and it was the combination of variables such as changes in heart rate, respiratory rate or blood pressure that led to the realization that the patient was potentially deteriorating and further assistance was sought.

Most studies related to the role of the nurse with respect to patient deterioration have centered on track and trigger systems, such as the modified early warning scoring system (MEWS) or rapid response systems (Ludikhuize et al. 2012, Odell et al. 2009, Considine 2005). Many issues that potentially influence patient outcomes have been identified including the adequacy of time to provide care, nurse to patient ratio and patient acuity level (De Meester et al. 2013, Doran et al. 2006). However, these are factors that are most often out of the control of individual nurses. This study focused on processes within the nurses' domain that are related to unexpected ICU admissions.

\section{Theoretical Framework}

The Nursing Role Effectiveness Model was used as the framework for this study. The Model helps to describe and understand the role of the nurse and the achievement of patient outcomes (Doran et al. 2006) and was used to identify the nursing process variables that would be measured in this study. The Nursing Role Effectiveness Model stems from Donabedian's Quality Framework (1996), which provides a guide in the evaluation of quality of health care. The Nursing Role Effectiveness model includes elements related to the evaluation of quality of nursing care and has helped to guide many research studies focused on quality health care improvement (Mitchell et al. 1998). As Donabedian's framework described quality according to three constructs: structure, process and outcomes, so too does the Nursing Role Effectiveness Model (Kelley et al. 2011). The Nursing Role Effectiveness Model represents the multidimensional nature of a nursing care situation. This model can be used as a framework to better understand the underlying mechanisms that nursing care has on patient outcomes (Irvine et al. 1998). 


\section{Figure 1,}

The Nursing Role Effectiveness Model (Irvine, Sidani, \& Hall, 1998).

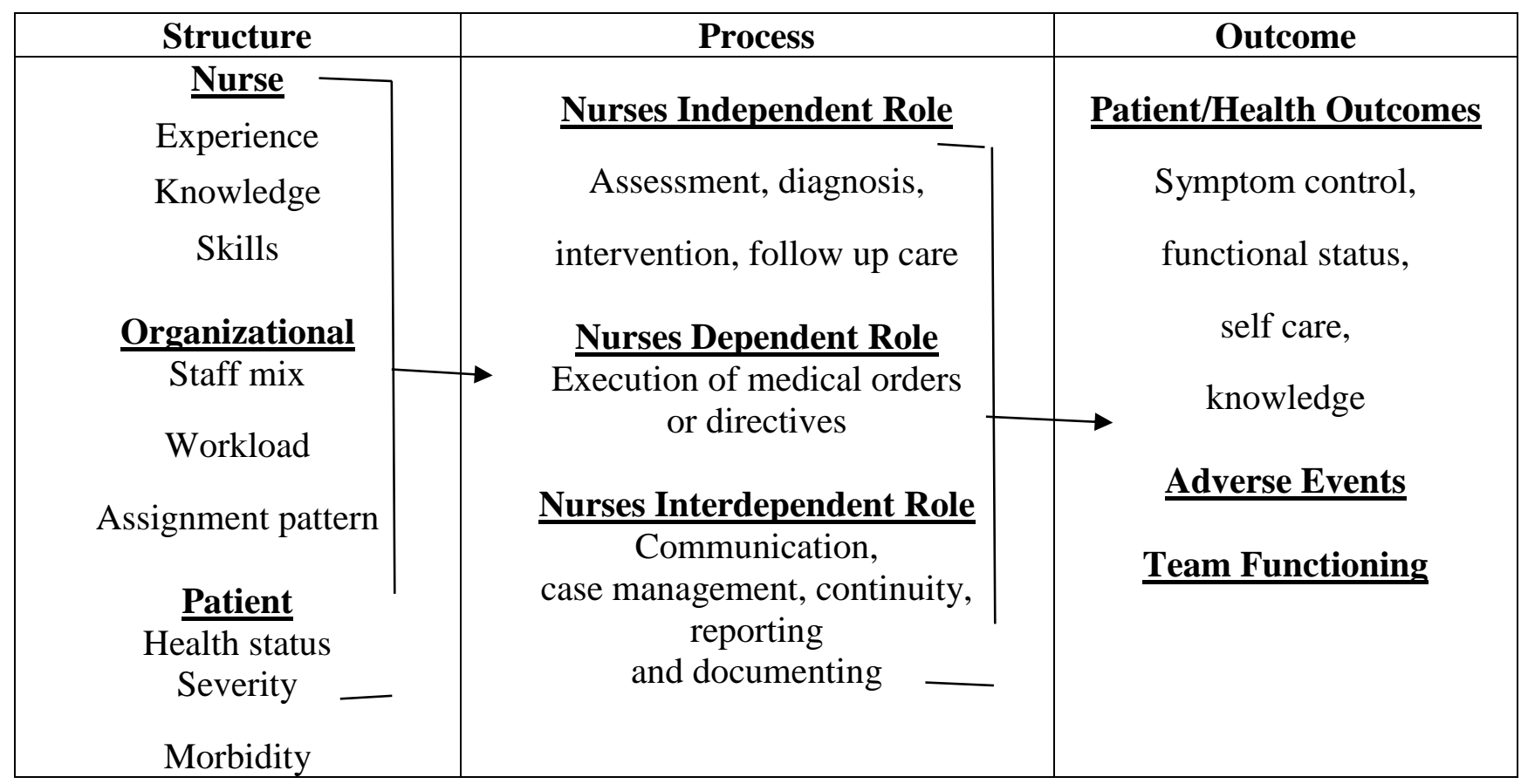

The focus of this study was in the evaluation of nursing processes. These include independent, dependent and interdependent actions that a nurse performs on an ongoing basis. Independent nursing actions are those that do not require a physician directive or order such as assessment, monitoring and evaluation of patient outcome. Dependent functions include those interventions that require a medical order such as the administration of medications. Interdependent functions include the collaboration of care that nurses share with other members of the health team to coordinate patient care, such as communication (Doran et al. 2002, Sidani \& Irvine 1999, Irvine et al. 1998).

Assessment is an element within the nurses' independent role. Vital signs are one component of the role of the nurse in all areas of the hospital (Yoost \& Crawford 2016) This type of assessment is essential in the recognition of patient deterioration and intervention.

An essential element of the interdependent role of the nurse is communication. Effective communication and sharing of patient information can prevent adverse events from occurring (Jukkala et al. 2012). Breaks in communication can lead to inconsistent patient care and lack of information on which to base decisions (Holly \& Politeck 2013, Anthony \& Preuss 2002). According to the USA's Joint Commission's Sentinel Event Database, communication breakdowns are part of the root cause of almost every event studied (Deering et al. 2011). Effective communication strategies can encourage the reporting of subtle signs of patient deterioration prior to the need for rapid intervention (Eberhardt 2014, Classen 2010). 
Documentation is another important interdependent role of the nurse and is a critical component of patient care and nursing practice. It allows for effective communication about the patient's condition and response to treatment (Kelley et al. 2011). Reasons for lack of documentation include: time constraints, lack of expertise and lack of monitoring equipment. Inadequate documentation may also result from a lack of resources, (Kohle-Ersher et al. 2012) workload difficulties, lack of guidelines for completing documentation and ambivalence towards documentation (De Meester et al. 2013). The amount of time required for documentation may also

play a role in how much information is recorded. When time is a barrier, documentation may be left until much later in the shift which can result in the loss of pertinent patient information and lead to undesirable outcomes, such as lack of recognition of patient deterioration and delayed intervention (De Meester et al. 2013).

Data collected in this study reflected the independent nursing role (vital signs) as well as the interdependent role (communication and documentation) and were used to determine nursing process factors that were associated with unexpected ICU admissions. The Nursing Role Effectiveness Model identifies that nursing staffing levels may impact nursing processes (see Figure 1), and since nursing staffing levels change on different times and days of the week, we also tracked the day of the week that the patient was admitted to ICU. In this study communication between the nurses and physicians and, or critical response team was identified in the nurses' documentation in the patient charts.

\section{Methods}

This study was a descriptive retrospective cohort design, which was a chart audit of patients admitted unexpectedly from the general wards to the medical surgical ICU of a large, urban hospital. Ethical approval for the study was received from Laurentian University and the hospital where the study took place.

The setting was a large teaching hospital in an urban centre in Canada. The hospital provides acute adult services with just over 460 inpatient beds. Many different specialties are part of the services provided to patients including neurosurgery, trauma, cardiovascular, orthopaedic and medical care. The hospital maintains a large roster of just over 6,000 staff members including 800 physicians and 1600 nurses. It is also a very active research facility with over 200 scientists and associate scientists. The hospital maintains four critical care units including a neurosurgical, cardiovascular, medical surgical and coronary care ICUs. It also has a critical care response team which serves all wards within the hospital.

\section{Chart Audit Tool}

An extensive review of the literature did not reveal any chart audit forms that focused specifically on the nursing processes targeted in this study that related to unplanned ICU admissions. A chart audit tool was created using the Nursing Role Effectiveness Model as a framework drawing items 
from the related literature as well as the nursing expertise of the research team. The final chart audit tool was used to collect information about communication and assessment for patients with unplanned ICU admissions. Communication was measured by the presence of documentation between the nurse and the most responsible physician (MRP) or to the critical care response team (CCRT). Assessment was reflected in the frequency of vital signs taken including pulse, respiratory rate, heart rate and oxygen saturation.

The chart audit tool also included patient demographic and health information including age, gender, co-morbidities, medical diagnosis and whether there was a previous ICU admission during the current hospitalization. In addition, the service that patients were admitted to, the ICU, the day of the week admission took place and the time that the patient was admitted were also collected. 


\section{Figure 2.}

Chart Audit Tool - Nursing Processes Related to Unplanned ICU Admissions

\begin{tabular}{|l|l|}
\hline Demographics \\
\hline Coded Identifier Number & \\
\hline Time Admitted & \\
(24 hour time) & \\
\hline Day of Week Admitted & \\
\hline Reason for admission & \\
\hline Co morbidities & \\
\hline Service admitted to & \\
\hline
\end{tabular}

\begin{tabular}{|l|l|}
\hline Demographics & Scores \\
\hline Age & \\
\hline Gender & \\
Male $=1$ & \\
Female $=2$ & \\
\hline Previous Admission to ICU & \\
Yes $=1$ & \\
No $=2$ & \\
\hline
\end{tabular}

\begin{tabular}{|l|l|l|}
\hline Communication and Documentation Questions & Scores & Notes \\
\hline Was there documentation of communication with MRP & & \\
Yes $=1 \quad$ No $=2$ & & \\
\hline Was there documentation of communication with RRT & & \\
Yes $=1 \quad$ No $=2$ & & \\
\hline $\begin{array}{l}\text { If there was communication with the MRP or RRT is there documentation } \\
\text { of intervention in nursing notes }\end{array}$ & & \\
Yes $=1 \quad$ No $=2$ & & \\
\hline Was there documentation of LOC (either GCS or narrative words alert, & \\
confused, unresponsive or similarities) & \\
Yes $=1 \quad$ No $=2$ & & \\
\hline Was there documentation of urine output & \\
Yes $=1 \quad$ No $=2$ & & \\
\hline $\begin{array}{l}\text { Was any information other than alert and oriented documented } \\
\text { Yes }=1 \quad \text { No }=2\end{array}$ & & \\
\hline \hline Data to be collected & & \\
\hline $\begin{array}{l}\text { Is there data missing from vital signs } \\
\text { Yes }=1 \quad \text { No=2 }\end{array}$ & & \\
\hline $\begin{array}{l}\text { If any data is missing from vital sign collection what is it } \\
\text { Temp }=1 \\
\text { Pulse }=2 \\
\text { Respiratory Rate }=3\end{array}$ & & \\
\hline
\end{tabular}


Blood pressure $=4$

Oxygen saturation $=5$

Systematic sampling was utilized by selecting the first 12 charts from each month over a 12-month time span that met the inclusion criteria. Inclusion criteria included patients over the age of 18 at the time of admission to hospital, who had subsequently been admitted, or readmitted to the medical surgical ICU. The sample was obtained by reviewing the admission book from the medical surgical ICU and determining what participants met the inclusion criteria. Data were collected by one researcher who scheduled time at the hospital in the medical records department to review the electronic medical records. A convenience sample of 144 charts was retrospectively analyzed. This number was chosen after it was determined to have sufficient power to address the planned statistical analysis (Faul, Erdfelder, Lang \& Buchner, 2007). The charts were reviewed in the order that they appeared in the admission book. Vital signs and documented and nursing narrative notes were reviewed. The researcher reviewed the charts and entered data into a separate excel file, indicating whether or not each specific nursing action was completed. The electronic charting system allowed for nurses to add as much detail about nursing care as required, such as multiple vital signs. The researcher added notes to identify such things as frequency of each vital sign that was taken.

\section{Results}

The sample was composed of $79(54.9 \%)$ male and $65(45.1 \%)$ female participants with a range of 20 to 91 . The mean age of people with an unplanned ICU admission was 58.8. Table 1 shows a breakdown of the age groups of patients in the study admitted to ICU.

\section{Table 1}

Age Breakdown of Patients Admitted to ICU

\begin{tabular}{ccc}
\hline Age Group & Frequency & Percentage \\
\hline 20 to 30 & 9 & $6.25 \%$ \\
31 to 40 & 12 & $8.3 \%$ \\
41 to 50 & 26 & $18.05 \%$ \\
51 to 60 & 24 & $16.6 \%$ \\
61 to 70 & 29 & $20.1 \%$ \\
71 to 80 & 29 & $20.1 \%$ \\
81 to 100 & 15 & $10.4 \%$ \\
\hline
\end{tabular}

Although admissions occurred every day of the week in the ICU, participants were most frequently admitted on Tuesdays with $26(18.06 \%)$ admissions. Mondays were the day of the week with the fewest admissions $16(11.11 \%)$ (See Figure 3$)$. Time data showed that most admissions $50(34.72 \%)$ occurred between the hours of noon and 1800 hours. This was followed by 39 
(27.08\%) admissions between 1800 and midnight, 34 (13.19\%) between midnight and 0600 hours and lastly 21 (14.58\%) occurred between 0600 and 1200 hours.

\section{Figure 3}

Day of Week of Admissions

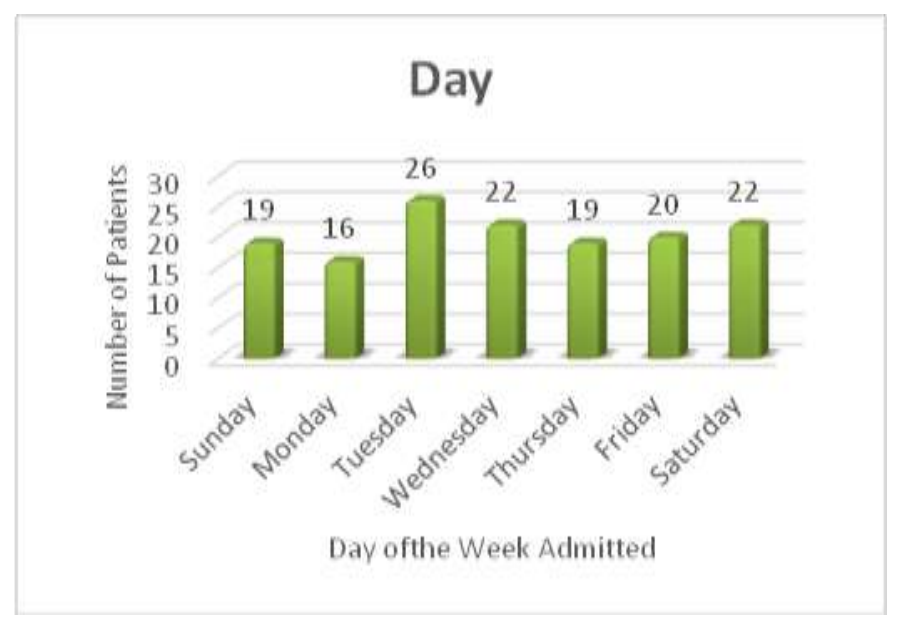

The most common reason for unplanned ICU admission was respiratory distress 76 (52.7\%). This included an admission diagnosis of pneumonia, cystic fibrosis exacerbation, chronic obstructive pulmonary disease (COPD), asthma exacerbation, respiratory arrest and bronchiectasis. Admitted participants had an average number of 3.5 co morbidities. The most common co morbidities documented in the chart were hypertension, diabetes mellitus and chronic obstructive pulmonary disease.

Patients from all services may be admitted to the medical surgical ICU. The frequencies of the admitted patients are explained in Figure 4.

\section{Figure 4}

Department Prior to ICU Admission

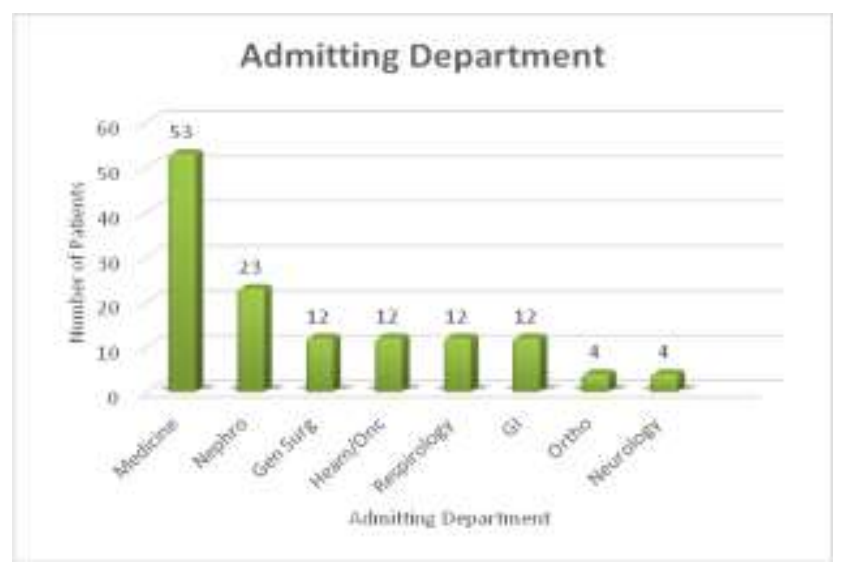


Communication with the most responsible physician was documented in the 12 hours prior to ICU admission in $119(82.6 \%)$ of the time while communication with the critical care response team was documented in 97 (67.3\%) of the charts reviewed prior to ICU admission. There was a significant medium negative correlation between the number of times that vital signs were taken in the 12 hours prior to ICU admission and communication with the most responsible physician $\left(r_{s}=-0.291, \mathrm{p}=.001\right)$ or the critical care response team $\left(r_{\mathrm{s}}=-254, \mathrm{p}=0.002\right)$.

The average number of times vital signs taken in the 12 hours prior to ICU admission was 3.4. There was no significant association between the frequency of vital signs $\left(\mathrm{r}_{\mathrm{s}}=0.026, \mathrm{p}=\right.$ $0.759)$, previous ICU admission $\left(\chi^{2}(1)=12.841 ; p=0.460\right)$, age $\left(x^{2}=684.995 ; p=0.871\right)$, gender $\left(x^{2}=14.681 ; p=0.328\right)$ and a diagnosis of respiratory distress. There was also no correlation between the frequency of vital signs taken for each patient and admission to the ICU for those with a diagnosis of respiratory distress $\left(r_{s}=0.026, p=0.759\right)$.

The documentation of the respiratory rate was missing in one or more sets of vital signs 56 (76\%) with an admitting diagnosis of respiratory distress and 51(73\%) in patients admitted with diagnosis of other illnesses. However, no significant association was found between an admitting diagnosis of respiratory distress and documented respiratory rates $\left(\chi^{2}(1)=.112 ; p=0.738\right)$, or whether oxygen saturations had been documented.

\section{Discussion}

The greatest number of participants who experienced an unplanned ICU admission while in hospital were between the ages of 61 to 80 . This is not surprising given that the average age of the population is increasing globally and people over the age of 80 are projected to make up $6.5 \%$ of the population in North America by the year 2050 (Bagshaw et al. 2009). Additionally, as people age the number of co morbidities increases which can lead to a significant health burden. People with multiple conditions have a lesser quality of life and require a greater number of health care resources (Canadian Institute for Health Information 2011). It is estimated that the need for ICU resources for those 80 and above will increase by $72 \%$ in the coming years (Bagshaw et al. 2009). Given the aging population with higher health care needs, it is increasingly important that ward nurses remain diligent in their assessments, documentation and communication to identify deterioration and prevent unexpected ICU admissions.

This study found that the most frequent day of admission was Tuesday and the most frequent time was between 1200 and 1800 hours. Nurse to patient ratios tend to decrease on night shifts (de Cordova et al. 2014). It is postulated that there is a higher level of surveillance present on wards during the weekdays and in the middle of the day when there are typically a higher percentage of nurses on duty as well as allied health staff. This could result in more timely identification of patient deterioration, resulting in the decision for admission to intensive care.

Perhaps the most interesting finding in this study was related to the frequency of vital signs. This study demonstrated that issues of the respiratory system were the most likely cause for urgent unplanned ICU admission. In fact, respiratory distress accounted for 53\% of all unplanned ICU 
admissions. Respiratory distress or symptoms of respiratory failure have also been the leading cause of unplanned ICU admissions in other research studies (Mohr et al. 2013, Jonsson et al. 2011).

Vital signs provide essential information about how the body is functioning and coping with illness. Alterations in vital signs can be indicative of the body's inability to cope with changes brought on by acute or chronic illnesses. Changes in vital signs may be present well before a patient acutely deteriorates (Mapp et al. 2013, Ludikhuize et al. 2012). The respiratory rate can be highly sensitive to changes in a patient's condition. Many studies have found that changes in vital signs, particularly respiratory rate, are present 8 hours prior to either cardiac arrest or unplanned ICU admission (Mapp et al. 2013, Cuthbertson et al. 2007). Clues to patient deterioration may be subtle early on but the respiratory rate is one that tends to increase prior to other vital signs (Curry \& Jungquist 2014).

Despite the importance of monitoring changes in respiratory rates, it was the least documented vital sign. There are a number of possible reasons that respiratory rate documentation was not associated with unplanned ICU admission. The importance of the respiratory rate is often under recognized by nurses and it receives a much lower priority than other vital signs (Cooper et al. 2012). In this study setting, vital signs are often taken by automated machines rather than by traditional observation and palpation. Automated machines typically do not count respiratory rates. Nurses may then quickly estimate respiratory rates based on previous documentation or expected norms (Cooper et al. 2012). It is quite possible that nurses inaccurately assess the respiratory rate by not actually counting the breaths per minute (Yuan et al. 2013). It has been found that when health care personnel have estimated the respiratory rate, the measured rate is often much higher than documented on reassessment (Philip et al. 2015). Despite this evidence, factors related to unexpected ICU admissions are complex and we express caution in consideration of respiratory rate alone.

The lack of adequate communication has been associated with many adverse events within the hospital setting (Manojlovich et al. 2015). Communication amongst health care professionals is essential for patient care. Effective communication skills and strategies allow for timely intervention when a patient is beginning to deteriorate (Classen 2010). As communication with the most responsible physician increased in this study, the number of times vital signs were taken decreased. The same held true for communication with the critical care response team. The reasons for these findings are not known. Nurses contact physicians or the critical care response team for direction when something changes in the patient's condition to obtain advice, or treatment orders. One interpretation of this finding is that nurses contacted the most responsible physician for consultation when they were concerned about the patient's condition. Once the physician or critical care response team was involved, the nurses may have felt the need for further evidence of vital sign deterioration was not necessary.

There are many limitations to retrospective chart audit research. A simple count of the frequency of communication with the most responsible physician or critical care response team 
and the frequency for which vital signs are taken, doesn't provide insight into the how this information influenced the care of the patients. Future research should focus on the nature of the communication between the nurse and most responsible physician or the critical care response team, follow up from either the nurse or the physician and prescription of medical interventions. Additional research should focus on the signs that nurses utilize to determine when a patient is deteriorating and which than prompts them to communicate with either the physician or the rapid response team.

\section{Relevance to Clinical Practice}

Nurses continuously gather information about their patient's health. The understanding and ability to further improve their patient's health can be obtained by further appreciating the importance of vital sign data, in particular the respiratory rate. One strategy to improve the detection of patient deterioration is to support the assessment of accurate respiratory rate counts. In understanding the value of abnormalities in vital signs more patients could be identified earlier which could lead to earlier intervention and therefore prevent the need for an ICU admission.

Communication, documentation and recognition of patient deterioration play a key role in preventing deterioration to the point of an unexpected ICU admission. Hospital management should be dedicated to improving these processes. One strategy may be to ensure adequate staffing, particularly on night shifts, so that ongoing assessments can be maintained. Staff inservices could focus on the importance of accurate vital sign assessments and a review of lines of communication. Tools to strengthen communication such as early warning scoring systems or SBAR (Situation, Background, Assessment and Recommendation) could be employed to empower nurses to communicate with physicians and the critical care response team earlier in regards to a patient's changing condition (Albert \& Huesman 2011). SBAR can help to improve the communication between nurses and physicians by providing a common way of organizing thinking in urgent situations. It can make the message that the nurse is attempting to convey more readily understood due to the preciseness of the information that is being delivered (Cornell et al. 2014).

\section{Conclusion}

In appreciating and critically appraising the vast amount of information that can be obtained from the collection of vital signs such as the respiratory rate nurses play a key role in helping to prevent patient deterioration. A stronger appreciation of and understanding of the nursing processes of communication, documentation and recognition of patient deterioration will aid in preventing unplanned intensive unit admissions and ultimately improve the outcomes of patients. 


\section{References}

Albert, B. \& Huesman, L. (2011). Development of a Modified Early Warning Score using the electronic medical record. Dimensions of Critical Care Nursing, 30(5), 283-292. doi: 10.1097/DCC.0b013e318227761d

Anthony, M. K., \& Preuss, G. (2002). Models of care: the influence of nurse communication on patient safety. Nursing Economic\$, 20(5), 209.

Ashcraft, A. (2004). Differentiating between pre-arrest and failure to rescue. MedSurg Nursing, 13(4), 211-216.

Bagshaw, S., Webb, S., Delaney, G., George, C., Pilcher, D., Hart, G. \& Bellomo, R. (2009). Very old patients admitted to intensive care in Australia and New Zealand: a multi-centre cohort analysis. Critical Care, 13(2), Retrieved from: http://dx.doi.org/10.1186\%2Fcc7768

Boyle, S. M. (2004). Nursing unit characteristics and patient outcomes. Nursing Economic\$, 22(3), 111.

Bradford, V. \& Grassi, F. (2009). Treatment of the Post-ICU Patient in an Outpatient Setting. American Family Physician. 79(6), 459-464.

Buist, M., Jarmoloski, E., Burton, P., Bernard, S., Waxman, B. \& Anderson, J. (1999). Recognizing clinical instability in hospital patient before cardiac arrest or unplanned admission to intensive care. A pilot study in a tertiary care hospital. The Medical Journal of Australia, 171(1), 22-25

Canadian Institute for Health Information, (2011). Seniors and the Health Care System: What is the impact of multiple chronic conditions? Retrieved from: https://secure.cihi.ca/free_products/air-chronic_disease_aib_en.pdf

Classen, J. L. (2010). Is failure to rescue really failure to communicate? Champion the move from reactive process to proactive model. Nursing Management, 41(7), 38-41. doi: 10.1097/01.NUMA.0000384034.25176.a2

Considine, J. (2005). The role of nurses in preventing adverse events related to respiratory dysfunction: literature review. Journal of Advanced Nursing, 49(6), 624-633

Cooper, S., Cant, R. \& Sparkes, L. (2012). Respiratory rate records: The repeated rate? Journal of Clinical Nursing, 23(9), 1236-1238. doi: 10.1111/jocn.12234

Cornell, P., Gervis, L., Yates, M. \& Vardaman, J. (2014). Impact of SBAR on nurse shift reports and staff rounding. MedSurg Nursing, 23(5), 334-342

Curry, J. \& Jungquist, C. (2014). A critical assessment of monitoring practices, patient deterioration and alarm fatigue on inpatient wards: a review. Patient Safety in Surgery, 8(29), 1-20. Retrieved from: http://www.ncbi.nlm.nih.gov/pmc/articles/PMC4109792/pdf/1754-9493-8-29.pdf

Cuthbertson, B., Boroujerdi, M., McKie, L., Aucott, L. \& Prescott. (2007).Can physiological variables and early warning scoring systems allow early recognition of the deteriorating 
surgical patient? Critical Care Medicine, 35(2), 402-409. doi:

10.1097/01.CCM.0000254826.10520.87

de Cordova, P., Phibbs, C., Schmitt, S. \& Stone, P. (2014). Night and day in the VA:

Associations between night shift staffing, nursing workforce characteristics and length of stay. Research in Nursing and Health, 37(2), 90-97. doi:10.1002/nur.21582. Retrieved from: http://www.ncbi.nlm.nih.gov/pmc/articles/PMC3959218/pdf/nihms-552094.pdf

Deering, S., Johnstone, L. \& Colacchio, K. (2011). Multidisciplinary team work and communication training. Seminars in Perinatology, 35(2), 89-96. doi:

10.1053/j.semperi.2011.01.009

De Meester, K., Van Bogaert, P., Clarke, S., \& Bossaert, L (2013). In hospital mortality after serious adverse events on medical and surgical wards: a mixed methods study. Journal of Clinical Nursing, 22 (15), 2308-2317. doi: 10.1111/j.1365-2702.2012.04154.X

Doran, D., Harrison, M. B., Laschinger, H., Hirdes, J., Rukholm, E., Sidani, S., . . Cranley, L. (2006). Relation between nursing interventions and outcome achievement in acute care settings. Research in Nursing \& Health, 29(1), 61-70.

Doran, D., Sidani, S., Keatings, M., \& Doidge, D. (2002). An empirical test of the Nursing Role Effectiveness Model. Journal of Advanced Nursing, 38(1), 29-39.

Eberhardt, S. (2014). Improving hand off communication with SBAR. Nursing, 44(11), 17-20. doi: 10.1097/01.NURSE.0000454965.49138.79

Elliott, D., Davidson, J., Harvey, M., Bemis-Dougherty, A., Hopkins, R., Iwashyna, T., Needham, D. (2014). Exploring the scope of post intensive care syndrome therapy and care: engagement of non critical care providers and survivors in a second stakeholders meeting. Critical Care Medicine, 42(12), 2518 - 2526. doi:

10.1097/CCM.0000000000000525

Garland, A., Olafson, K., Ramsey, C., Yogendran, M., \& Randall, F. (2013). Epidemiology of critically ill patients in ICUs: a population based observational study. Critical Care, 17(5). http://doi.org/10.1186/cc13026

Harvey, M. (2012). The truth about consequences-Post-intensive care syndrome in intensive care unit survivors and their families. Critical Care Medicine, 40(8), 2506-2507. doi: 10.1097/CCM.0b013e318258e943

Holly, C. \& Politeck, E. (2013). A systematic review on the transfer of information during nurse transitions in care. Journal of Clinical Nursing, 23(17-18), 2387-2396. doi: 10.1111/jocn. 12365

Irvine, D., Sidani, S., \& Hall, L. M. (1998). Linking outcomes to nurses' roles in health care. Nursing Economic\$, 16(2), 58.

Jäderling, G., Bell, M., Martling, C., Ekbom, A., Bottai, M., \& Konrad, D. (2013). ICU admittance by a rapid response team versus conventional admittance, characteristics, and outcome. Critical Care Medicine, 41(3), 725-731. doi:10.1097/CCM.0b013e3182711b94 
Jeffs, L., Law, M., Baker, G., \& Norton, P. (2005). Patient Safety Research in Australia, United Kingdom, United States and Canada. Canadian Patient Safety Institute. Retrieved from: http://www.patientsafetyinstitute.ca/English/news/eventProceedings/Documents/2005\%2 0Research\%20Retreat\%20\%20Patient\%20Safety\%20Research\%20Backgrounder\%20Paper.pdf

Johns, T. (2014). Characteristics and Risk Factors of Trauma Patients Readmitted to the ICU within the same Hospitalization. Journal of Trauma Nursing, 21(1), 14. doi:10.1097/JTN.0000000000000023

Jonsson, T., Jonsdottir, H., Möller, A. \& Baldursdottir, L. (2011). Nursing documentation priorto emergency admissions to the ICU. Nursing in Critical Care, 16 (4), 164-169.

Jukkala, A., James, D., Autrey, P., Azuero, A. \& Miltner, R. (2012). Developing a standardized tool to improve nurse communication during shift report. Journal of Nursing Care Quality, 27(3), 240-246. doi: 10.1097/NCQ.0b013e31824ebbd7

Kelley, T., Brandon, D., \& Docherty, S. (2011). Electronic nursing documentation as a strategy to improve quality of patient care. Journal of Nursing Scholarship, 43(2), 154-162. doi: 10.1111/j.1547-5069.2011.01397.x

Kohle-Ersher, A., Chatterjee, P., Osmanbeyoglu, H., Hochheiser, H. \& Bartos, C. (2012). Evaluating the barriers to point of care documentation for nursing staff. Nursing, 30(3), 126-133. doi: 10.1097/NCN.0b013e3182343f14

Lee, J., Park, S., Kim, H., Hong, S., Lim, C., Koh, Y. (2009). Outcome of early intensive care unit patients readmitted in the same hospitalization. Journal of Critical Care, 24 (2) $267-$ 72. doi:10.1016/j.jcrc.2007.12.019

Ludikhuize, J., Smorenburg, S., de Rooij, S., \& de Jonge, E. (2012). Identification of deteriorating patients on general wards; measurement of vital parameters and potential effectiveness of the Modified Early Warning Score. Journal of Critical Care, 27(4), 424.37-424.e13. doi:10.1016/j.jcrc.2012.01.003

Manojlovich, M., Harrod, M., Holtz, B., Hofer, T., Kuhn, L. \& Krein, S. (2015). The use of multiple qualitative methods to characterize communication events between physicians and nurses. Health Communication, 30(1), 61-69. doi: 10.1080/10410236.2013.835894

Mapp, D., Davis L. \& Krowchuk, H. (2013). Prevention of Unplanned Intensive Care Unit Admissions and Hospital Mortality by Early Warning Systems. Dimensions of Critical Care Nursing, 32(6), 300-309. doi: 10.1097/DCC.0000000000000004

Mitchell, I., McKayb, H., VanLeuvan, C., Berry, R., McCutcheon, C., Avarda, B., Slater, N., ...\& Lamberth, P. (2010). A prospective controlled trial of the effect of a multi-faceted intervention on early recognition and intervention in deteriorating hospital patients. Resuscitation, 81(10), 658-666. doi:10.1016/j.resuscitation.2010.03.001

Mohr, J., Lourenco, M., Cooke, R., \& Aitken, M. (2013). Characteristics and outcomes of patients requiring unplanned transfer from sub acute to acute care. International Journal of Nursing Practice, 19 (2), 186-96. doi:10.1111/ijn.12056 
Mok, W., Wang, W. \& Liaw, S. (2015).Vital signs monitoring to detect patient deterioration: An integrative literature review. International Journal of Nursing Practice, 21, Suppl.2, 9198. doi:10.1111/ijn.12329

Odell, M., Victor, C. \& Oliver, D. (2009). Nurses role in detecting deterioration in ward patients; systematic literature review. Journal of Advanced Nursing, 65(10), 1992-2006. doi: 10.1111/j.1365-2648.2009.05109.x

Philip, K., Pack, E., Cambiano, V., Rollman, H., Weil, S. \& O’Beirne, J. (2015). The accuracy of respiratory rate assessment by doctors in a London teaching hospital: a cross sectional study. Journal of Clinical Monitoring and Computing, 29(4), 455-460. doi: 10.1007/s10877-014-9621-3

Ratray, J., Lauder, W., Ludwick, R., Johnstone, C., Zeller, R., Winchell, J., ... Smith, A. (2011). Indicators of acute deterioration in adult patients nursed in acute wards: a factorial survey. Journal of Clinical Nursing, 20(5), 723. doi: 10.1111/j.1365-2702.2010.03567.x

Sidani, S., \& Irvine, D. (1999). A conceptual framework for evaluating the nurse practitioner role in acute care settings. Journal of Advanced Nursing, 30(1), 58-66. doi:10.1046/j.13652648.1999.01049. $\mathrm{x}$

Soar, J. \& Subbe, C. (2012). Identifying the patient at risk of deterioration, ICU admission or cardiac arrest: Stop predicting, start preventing. Critical Care Medicine(40)7, 2243-2247.

Yoost, B. \& Crawford, L. (2016). Fundamentals of Nursing: Active Learning for Collaborative Practice. St. Louis, Missouri: Elsevier

Yuan, G., Drost, N. \& McIvor, R. (2013). Respiratory rate and Breathing Pattern. McMaster University Medical Journal, 10(1), 23-25. Retrieved from: http://www.mumj.org/Issues/v10_2013/articles/v10_23.pdf 